\title{
The Use of Geoinformatics for Estimating Soil Organic Matter in Central Plain of Thailand
}

\author{
Prapeut Kerdsueb and Piyakarn Teartisup
}

\begin{abstract}
LANDSAT TM 5; band 1-3-4 was used to predict soil organic matter contents in central plain of Thailand: Nakhon Pathom province as a representative area. There were 135 plots from several agricultural land use; paddy fields, sugarcane and fruit orchard. $Y=3.926+0.0176 \quad X 1-0.0117$ $X 3+0.0476 X 4\left(R^{2}=0.357\right)$ was the result from the interpolation method at RMSE $=0.95$. The soil organic matter map was build up via Geoinformatics techniques with additional data sources. These techniques include organic matter models and qualitative methods. Finally, validation methods used to assess the accuracy of maps produced with image data are discussed. It is concluded that a general lack of validation data is a main concern. Validation is of utmost importance to achieve regional operational monitoring systems, and close collaboration between the image data and field-based soil scientists is therefore required.
\end{abstract}

Index Terms - Geoinformatics, soil organic matter, inverse distance weighted.

\section{INTRODUCTION}

Thailand (total area: $513,115 \mathrm{~km}^{2}$ ) covers much of the central, southern, and western parts of mainland Southeast Asia. Central of Thailand comprises the flat plains of the Chao Praya River Basin. An area ideal for paddy filed [1] in order that the soil resource is the important factor. Soil organic matter (SOM) is an extremely important component of soil. It provides nutrients for crops as it decomposes and contributes to the cation exchange complex necessary for holding applied nutrients in the soil. Soil aggregation is improved by increased organic matter content and hence has a role in maintaining soil structure, drainage and aeration all of which are necessary for good crop yields. SOM also plays a role in increasing moisture retention and consequently the drought tolerance of the crop [2]. The organic matter in soil derives from plants and animals. When the organic matter has broken down into a stable humid substances that resist further decomposition it is called humus. Thus SOM comprises all of the organic matter in the soil exclusive of the undecayed material. Therefore, sufficient SOM will help increasing yield of plants because organic matter acts as a major source in absorbing and releasing soil nutrients to plants during their growth stage. The organic matter was decreased by agricultural practice; mono crop; pesticide eradication; and economic growth. All causes influence to high and rapid loss of nutrients which are not renewable by the natural process. In addition, various technologies for plant production are

Manuscript received August 9, 2013; revised October 20, 2013.

Prapeut Kerdsueb and Piyakarn Teartisup are with the Faculty of Environment and Natural Resource Studies, Mahidol University, Thailand (e-mail: peat2u@yahoo.com; piyakarn.tea@mahidol.ac.th). applied such as improvement of plant breeding for high crop production, short-term cultivation, all-season cultivation, and irrigated system management. These factors lead to more rapid loss of soil nutrients. However, utilization of fertilizer synthesized by human in various types and quantities according to their needs would lead to higher cost of production as well as affect the quality of the cultivation area [3]. Soil qualities in Thailand were loosed of such as organic matter and plant nutrients under different types of soil management [4]. Nakhon Pathom province is in central plain of Thailand that was many land use activities and also various agricultural land use type. Thus, this province was an interesting site to estimating soil organic matter.

Geoinformatics is a science which develops and uses information science infrastructure to address the problems of geosciences and related branches of environmental management [5]. This research aimed to study soil organic matter contents to analyze spectral reflectance particularly of agricultural land by Geoinfromatics such as Global Positioning System/ GPS [6], Remote Sensing (satellite data: LANDSAT TM 5) and Geographical Information System/ was analyzed in relation to soil organic matter, which the data were interpolated by means of the Inverse Distance Weighted (IDW) [7] method for estimate soil organic matter. Beside, the Root Mean Square Error (RMSE) method was applied to validate the IDW. The results were illustrated by SOM maps of study area.

\section{METHODS}

\section{A. Soil Property Analysis}

Nakhon Pathom was selected as sampling site of the central plain of Thailand. 135 plots (120 sampling plots, 15 reference plots) were covered with paddy fields, sugarcane fields and fruit orchards. Each soil plot, 1 composite sample $(0-30 \mathrm{~cm}$.) was collected soil properties analysis. We used LANDSAT TM 5 data in same date that collect the soil. The soil properties were analysis as follow color by USDA soil manual, texture by hydrometer method, soil reaction by $\mathrm{pH}$ meter (1:1), soil moisture by saturation percentage hydrometer method, and soil organic matter were analyzed by Walkley and Black Method [8].

\section{B. Data Manipulation}

Co-ordination sampling site data from filed sampling and soil properties analysis were in put to Geospatial Image processing with ERDAS IMAGINE which LANDSAT TM 5 for find out the relationship between spectral reflectance and SOM content. Multiple regression analysis method was use to find the relationship between digital number value from 
Image data (band 1-5 and band 7) and OM. Geostatistical Analysis Extension of ArcGIS was manipulated Spatial Interpolation Method: Inverse Distance Weighted (IDW) for estimating of SOM and illustrated by SOM maps. Root Mean Square Error (RMSE) method was applied to validate the IDW for estimate soil organic matter.

\section{RESULTS AND DISCUSSIONS}

\section{A. Soil Properties}

Soil representative of this study as show below:

1) soil organic matter: fruit orchard and sugarcane field were medium while paddy filed was moderately high,

2) soil reaction: fruit orchard and sugarcane field were neutral but paddy filed was slightly to medium acidic,

3) soil color: all land use were very dark brown to black,

4) soil moisture: sugarcane field and paddy filed was 0-10 $\%$ of soil moisture while fruit orchard was $0-10 \%$ and $10-20 \%$ of soil moisture,

5) soil texture: fruit orchard and paddy filed were fine-texture while sugarcane field was fine-texture and coarse-texture.

The landform of study area was divided into 3 types; former tidal flats, flood plains, and alluvial terraces. The materials have high uniformity of texture (clay, silt and sandy clay) covering the majority of the fields and affecting soil fertility. Paddy field soil was found to be suitable for plant growth as same as fruit orchard which have a moderately high level of soil organic matter content. Sugarcane soil was different from the other two areas, because sugarcane cultivation absorbs more nutrients. However, some soil samples of each of land use had low values because of lacking of land improvement and mono-crop rotation.

\section{B. Relationship between Spectral Reflectance Factors and Soil Organic Matter Content}

Multiple regression analysis method was use to find the relationship between organic matters and digital number value from LANDSAT TM 5 data (Fig. 1). Six independent variables and soil organic matter content revealed a negative correlation $(R=-0.257,-0.158,-0.074,-0.274,-0.268$ and -0.208 , respectively), with quite low rates of relationships among independent variables and the dependent variable. Correlation coefficient value between soil organic matter and band 4 was -0.274 . The relationships were low because the distortion of spectral reflectance value was due to the plants coverage over the area and researchers could not collect soil samples after harvest period due to 3 agricultural land use (paddy fields, sugarcane fields, fruit orchards) are different harvest periods. This point affect to the inaccurate value of spectral reflectance. Finally, Normalized Difference Vegetative Index (NDVI) found that values indicated non-vegetated as $43.2 \%$ and values indicated vegetated as $56.8 \%$ with spectral confusion.

\section{Soil Organic Matter Content Forecasting Models}

The independent variables were used in stepwise regression analysis, the output showed the frequency of band $1(X 1)$, band $3(X 3)$ and band $4(X 4)$ which is employed into the model with statistical significant level at $0.05(F<0.05)$ as shown in (1):

$$
Y=3.926+0.0176 \times 1-0.0117 \times 3+0.0476 \mathrm{X}
$$

From mathematic model, multiple correlation coefficients (Table I) were $0.570(R)$ while coefficient of determination $\left(R^{2}\right)$ was 0.325 . Soil organic matter content $(Y)$ could be explained through independent variables band $4(X 4)$, band 1 $(X 1)$ and band $3(X 3)$ by 32.5 percent. The error of model was 1.08631 .
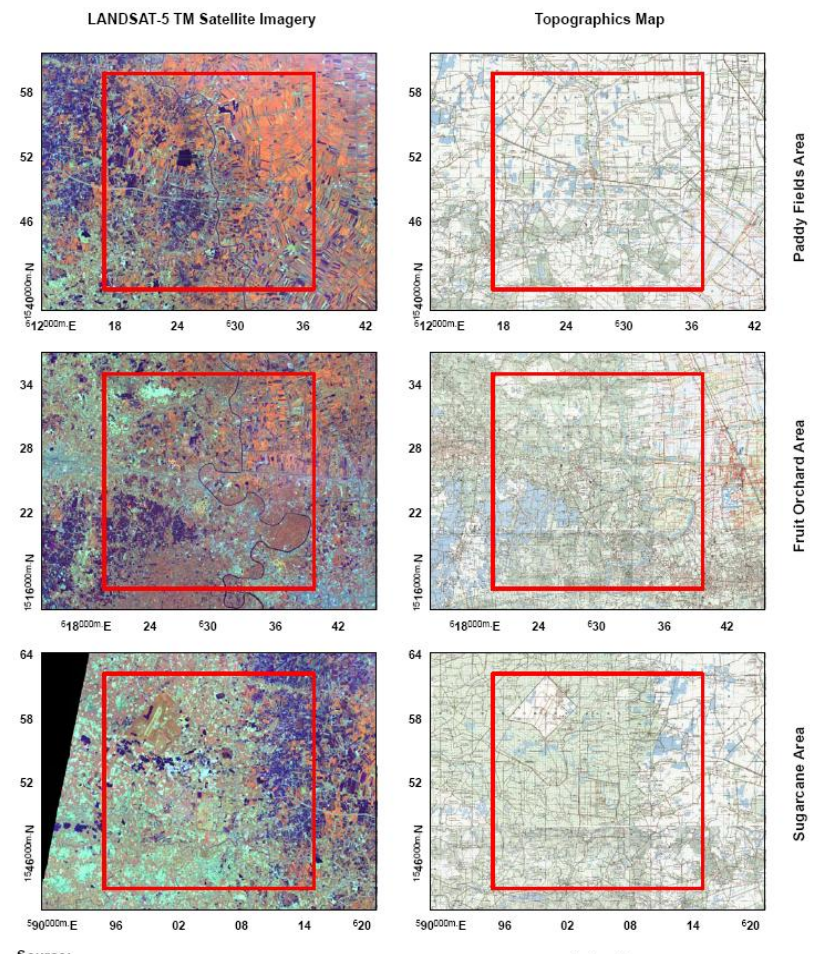

$$
\text { Source: }
$$

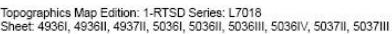

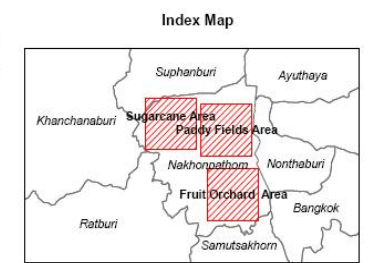

Fig. 1. LANDSAT TM 5 data covered paddy field, sugarcane field, and fruit orchard areas.

TABLE I: STATISTICAL OUTPUT OF REGRESSION MODEL (1)

\begin{tabular}{ccccccc}
\hline \hline Model & $\begin{array}{c}\text { Independent } \\
\text { variable } \\
\text { (Constant) }\end{array}$ & \multicolumn{2}{c}{$\begin{array}{c}\text { Unstandardized } \\
\text { Coefficients }\end{array}$} & \multicolumn{2}{c}{$\begin{array}{c}\text { Standardized } \\
\text { Coefficients }\end{array}$} & Significant \\
\cline { 3 - 6 } & & $\mathrm{B}$ & $\begin{array}{c}\text { Stand } \\
\text { error }\end{array}$ & Beta & $\mathrm{T}$ & \\
\hline No. & & 3.926 & 1.908 & - & 2.058 & 0.042 \\
1 & Band 1 $(X 1)$ & $1.760 \mathrm{E}-02$ & 0.037 & 0.084 & 0.476 & 0.635 \\
2 & Band 3(X3) & $-1.17 \mathrm{E}-02$ & 0.021 & -0.094 & -0.549 & 0.585 \\
3 & Band 4(X4) & $-4.76 \mathrm{E} 02$ & 0.007 & -0.572 & -6.420 & 0.000 \\
\hline
\end{tabular}

$R=0.570, R^{2}=0.325, F=15.431$, Sig. of $F=0.000$

According to the result found that remote sensing capabilities and their application for detecting soil organic matter can related in general soil reflectance was low but increases monotonically with wavelength through the visible and near-infrared portions of electromagnetic spectrum [9] which soil organic matter has been correlated with visible and NIR reflectance in many studies [10], [11]. Soil organic matter has been related to reflectance data collected over 
agricultural fields in several studies [3], [12], [13].

\section{Interpolation Method and Validation}

Soil organic matter was estimated by spatial interpolation method using inverse distance weighting (IDW) and Spatial Analyst Extension. Based on the Inverse distance weighting, the nearby values contribute more to the interpolated values than distant observations. In other way, the influence of a known data point was inversely related to the distance from the unknown location that was being estimated. The advantage of IDW is that it is intuitive and efficient. Selecting an appropriate spatial interpolation method is important [14]. The appropriate equation from multiple linear regression models was build grid point for manipulate the digital number and interpolate organic matter map (Fig. 2). The final grid point can refer to soil organic matter and map (Fig. 3).

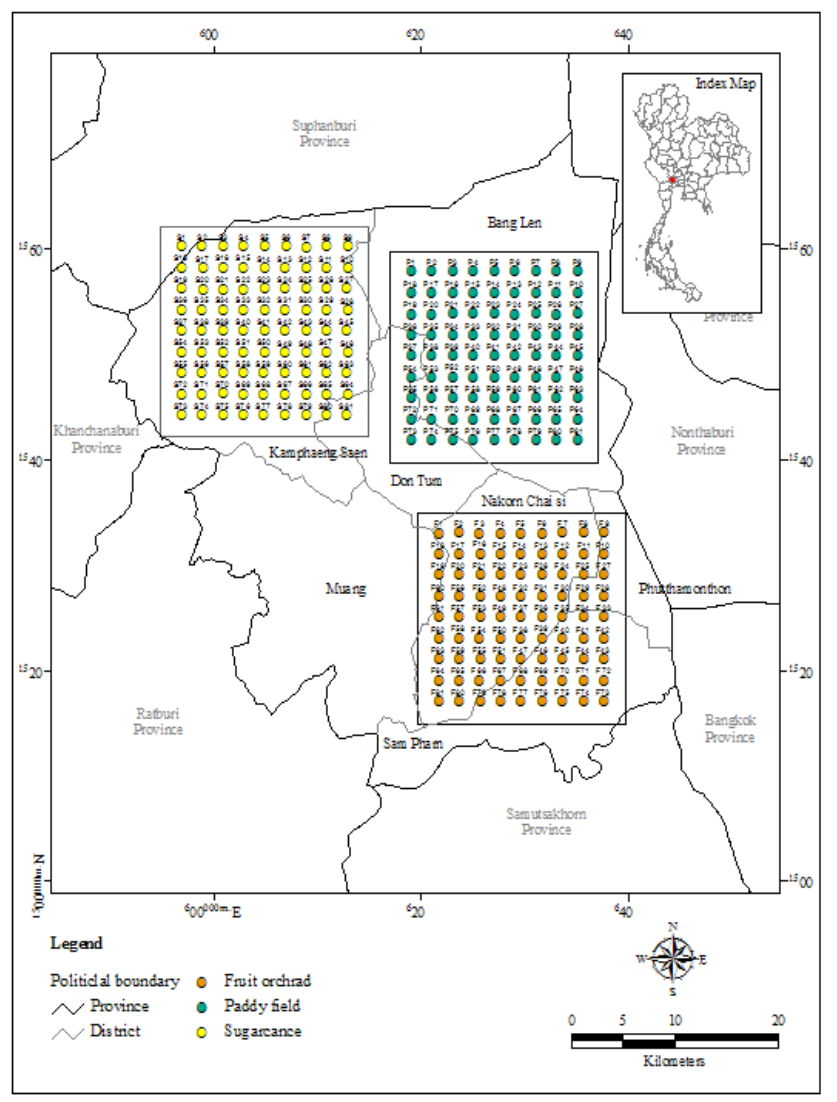

Fig. 2. Grid point in field study.

Finally, the validation test was the last step of interpolation in order to ensure accuracy before using map. The interpolations were a cross validation for methods where the interpolation error, root mean square error (RMSE) that will judge the effectiveness of method in reproducing the original data set. The least root mean square error (RMSE) could prove that the model result was correct. Statistical evaluation methods, such as regression parameters and root mean squared error (RMSE) represented as a percentage of the observed mean values. The RMSE value was 9.98. The results show that, with some ground truthing, aerial hyper spectral imagery can provide useful information for SOM estimation. Result estimating validation could be verified by the reference. It found that RMSE $=0.95$ which the least value it means that interpolating surfaces in ArcGIS Spatial
Analyst Inverse Distance Weighting.

\section{CONCLUSION AND RECOMMENDATIONS}

The relationship between spectral reflectance and soil organic matter content were from band $1(X 1)$, band $3(X 3)$ and band $4(X 4)$. It found that there are 3 independent variables at significant statistical level $0.05(F<0.05)$. The multiple correlation coefficients was $0.570(R)$, while adjusted $R^{2}$ was 0.325 .

This model had predicted an error of 1.08631 which related to soil reflectance in remote sensing theory. In general soil reflectance was low but increased moronically with wavelength through the visible and near-infrared portions of electromagnetic spectrum. Thus, the study result found that the bands that could reflect organic matter are band $1(X 1)$ and band $3(X 3)$ in visible wavelength and band $4(X 4)$ in near-infrared wavelength which matched the theories.

It was found that relationship between spectral reflectance and soil organic matter content for soil reflectance in the agricultural area were not high because the digital number of image processing each pixel had moderately high intensity value (represented by a digital number), which caused spectral confusion, masking different organic matter level, where, the type and abundance of vegetation cover.

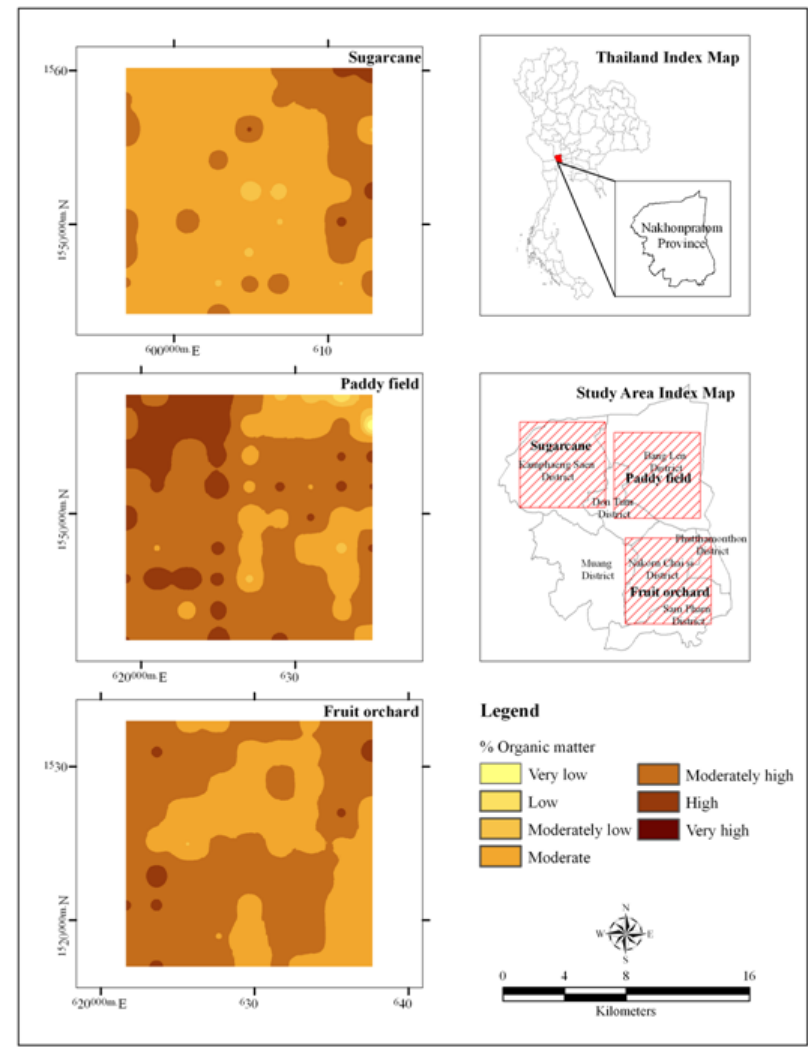

Fig. 3. Map of SOM in study area by IDW method.

The lesson learns from this research were 1) lack of specific absorption bands of some soil properties and occurrence of spectral confusion, and 2) low spectral resolution of satellite bands. Soil organic matter represents an increasing environment, especially in pain area. This calls for estimating to support timely decision making on land management, reclamation, and rehabilitation. Estimating soil 
organic matter is greatly enhanced when using multispectral Remote sensing data and Geoinformatics, which however need transformation before being used for Identification and change detection. Detecting and assessing change between a current and a past situation involve uncertainties about likelihood, nature, and magnitude of the changes, which can be solved using expert knowledge. The best estimating results are obtained when integrating Geoinformatics with filed and laboratory data. In this regard, Geoinformatics offer the advantage of integrating data of diverse nature in terms of scale time, source, and structure. It is the research's challenge to identify the most appropriate ground and Geoinformatics techniques can be applied to extract information in an accurate and cost-effective manner [15]. Therefore, the next research should be consider in soil properties which are used as factors in the equation, because soil reflectance properties depend on numerous soil characteristics, such as mineral composition, texture (particle size), structure (surface roughness), percentage of organic matter, and moisture contents [16]. These factors are complex, variable, and interrelated. Mineral composition, organic matter and moisture content which are the main factors governing spectral absorption of radiation and collection of the soil samples should be widely distributed with more areas of sample collection because interpolation method makes assumptions of how to determine the estimated values for more accuracy and reliability.

\section{REFERENCES}

[1] A. Ali, K. Will, and C. R. Jeremy, Environments in Transition: Cambodia, Lao PDR, Thailand, Viet Nam, Manila, Philippines: ADB, 2001.

[2] A. Bot and J. Benites, The Importance of Soil Organic Matter: Key to Drought-Resistant Soil and Sustained Food Production, Rome, Italy: FAO, 2005.

[3] F. Chen, E. D. Kissel, T. W. Larry, and A. Wayne. (October 2005). Field-scale mapping of surface soil organic carbon using remotely sensed imagery. Soil Science Society of America Journal. [Online]. 64(2). pp. 746-753. Available: http://www.Soil.scijournas.org/cgi/content/abstract/64/2/746

[4] S. Sombatpanit, C. W. Rose, C. A. Ciesiolka, and K. J. Coughlan, Soil and Nutrient Loss under rozelle (Hibiscus Subdariffa L. Var. Altissima) at Khon Kaen, Thailand, Bangkok, Thailand: Dep. of Land Development, 2006.

[5] P. Teartisup, Geoinformatics for the Environment, Nakhon Pathom, Thailand: Mahidol Univ., 2007.

[6] L. Alfred, GPS Satellite Surveying, New York, USA: Wiley, 1995.

[7] P. Teartisup, P. Kerdsueb, and P. Wattaya, "Field scale mapping of soil salinity on spatial interpolation techniques, case study: Khorat Basin, Nakhon Ratchasima Province, Thailand," Environmental Informatics Archives, vol. 5, pp. 524-547, 2007.

[8] NRCS, United States Dep. of Agriculture. (June 2005). Soil survey Laboratory methods manual, version 4.0, 2004. [Online]. Available: ftp://ftp-fc.sc.egov.usda.gov/NSSC/Lab_Methods_Manual/SSIR42_2 004_view.pdf

[9] P. J. Curran, G. M. Foody, K. Y. Kondratyev, V. V. Kozoderrov, and P. P. Fedchenko, Remote Sensing of Soils and Vegetation in the USSR, London, England: Taylor \& Francis, 1990.
[10] P. Krishnan, J. D. Alexander, B. J. Butler, and J. W. Hummel, "Reflectance technique for predicting soil organic matter," Soil Science Society of America Journal, vol. 44, pp. 1282-1285, 1980.

[11] E. R. Stoner and F. Baumgardner, "Characteristic variations in reflectance of surface soils," Soil Science Society of America Journal, vol. 45, pp. 1161-1165, 1981.

[12] T. L. Coleman, P. A. Agbu, O. L. Montgomery, T. Gao, and S. Prasad, "Spectral band selection for quantifying selected proper-ties in highly weathered soils," Soil Science, vol. 151, no. 5, pp. 355-361, 1991.

[13] T. L. Henderson, M. F. Baumgardner, D. P. Franzmeier, D. E. Stott, and D. C. Coster, "High dimensional reflectance analysis of soil organic matter," Soil Science Society of America Journal, vol. 56, no. 3, pp. 865-872, 1992.

[14] D. E. Meyers. (January 2007). Spatial interpolation: An overview. Geoderma. [Online]. 6(1-3). pp. 17-28. Available: http://www.sciencedirect.com/science/journal/00167061

[15] G. I. Metternich and J. A. Zinck. (January 2007). Remote sensing of soil salinity: potentials and constraints. Remote Sensing of Environment. [Online]. (85). pp. 1-20. Available: http://www.elsevier.com/locate.rse

[16] T. M. Lillesand and R. W. Kieffer, Remote Sensing and Image Interpretation, 2nd ed. New York, USA: John Wiley and Sons, 1987.

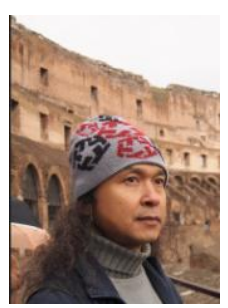

Prapeut Kerdsueb was born in 1966 in Thailand. He is a lecturer at Faculty of Environment and Natural Resource Studies, Mahidol University more over 15 years. His papers include: $P$. Teartisup and $P$. Kerdsueb, Application Of ROS for Ecotourism Zoning at Lopburi Province. Environment and Natural Resources Journal, Mahidol Univ. 2005; Year 3 : 105-113, P. Teartisup, P. Kerdsueb and P. Wattaya. Field Scale Mapping of Soil Salinity on Spatial Interpolation Techniques, Case Study: Khorat Basin, Nakhon Ratchasima Province, Thailand International Society for Environmental Information Sciences Environmental Informatics Archives. ISSN 1811-0231/ ISEIS Publication Series Number P002 Copyright (C) 2007 ISEIS; 524-547, Teartisup P, Kerdsueb P. Application of Mike 11 for water quality assessment at U-Tapao canal, Southern of Thailand. KUU Science J 2011; 39: 649-663, and P. Teartisup and P. Kerdsueb Land Subsidence Prediction in Central Plain of Thailand International Journal of Environmental Sciences and Development 2013; 4: 59-61.

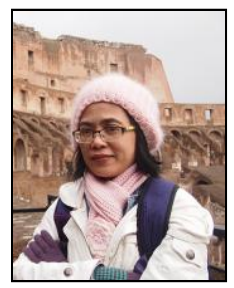

Piyakarn Teartisup was born in 1967 in Bangkok, Thailand. She got Ph.D. from Kasetsat University in Forestry-Watershed Management and as a lecturer at Faculty of Environment and Natural Resource Studies, Mahidol University more over 15 years. In 2010, she attended the training course on traditional forest knowledge held within the framework of XXIII IUFRO world congress in Republic of Korea. Her papers include: P. Teartisup, P. Kerdsueb and P. Wattaya. Field Scale Mapping of Soil Salinity on Spatial Interpolation Techniques, Case Study: Khorat Basin, Nakhon Ratchasima Province, Thailand. International Society for Environmental Information Sciences Environmental Informatics Archives. ISSN 1811-0231/ ISEIS, p 524-547, 2007, Piyakarn Teartisup and Prapeut Kerdsueb. Application of Mike 11 for Water Quality Asseement at U-Tapao Canal, Southern of Thailand, KKU Science Journal, Faculty of Science, Khon Kaen University, Thailand, vol. 4, year 39, pp. 649-663, 2012, and P. Teartisup and P. Kerdsueb Land Subsidence Prediction in Central Plain of Thailand International Journal of Environmental Sciences and Development 2013; 4: 59-61. 